Research Article

\title{
Complexion and Conviction for Consumption of Narcotic and Psychotropic Substances: An Analysis of Health Survey in All Over India
}

\author{
Megha Shah*1, Harshwardhan S Patil2 ${ }^{2}$, Vaibhavi Mulley², Anand Dhumal2 ${ }^{2}$, Dr Ashwini Madgulkar ${ }^{3}$ \\ 1. Assistant Professor of Pharmacognosy, AISSMS college of Pharmacy, Pune, Maharashtra, India. \\ 2. Students of AISSMS College of Pharmacy, Pune, Maharashtra, India. \\ 3. Principal of AISSMS College of Pharmacy, Pune, Maharashtra, India. \\ *Corresponding author's E-mail: meghashah88@gmail.com
}

Received: 13-11-2021; Revised: 24-01-2022; Accepted: 03-02-2022; Published on: 15-02-2022.

\section{ABSTRACT}

Substance use is ubiquitous with a range of substances being abused the world over. India has a large consumer base of different substance abusers. This has serious repercussions in terms of morbidity \& mortality. Narcotic drugs mean those drugs which induce sleep while Psychotropic drugs are those who impact on the mind and alter the ability of mind of the people. There has been increasing the incidence of addiction to certain drugs amongst people belonging to various strata of society particularly amongst young people in our country. This case study was done with reference to INDIA, to determine the prevalence, state wise trends, consumption of drug among different age group, education qualification of those who are taking drugs, which drug is consumed the most and the licit production of OPIUM according to Indian Government and causes of taking psychotropic substances. It is alarming condition that about $70 \%$ of the drug abusers falls in the age group of $20-40$ years old, ultimately resulting in increased suicide cases. According to the Ministry of Social Justice and Empowerment, Government of India and AlIMS only $1 / 4$ th(25 percent) of drug abusers receive treatment and rest of them do not receive any treatment. A more intensive research, action programme, and social movement are needed. It is also needed to strengthen family and social values and religious ethics in order to maintain a stable and drug-free society

Keywords: Narcotics drugs, Psychotropic substance, Drug abuse, licit production.

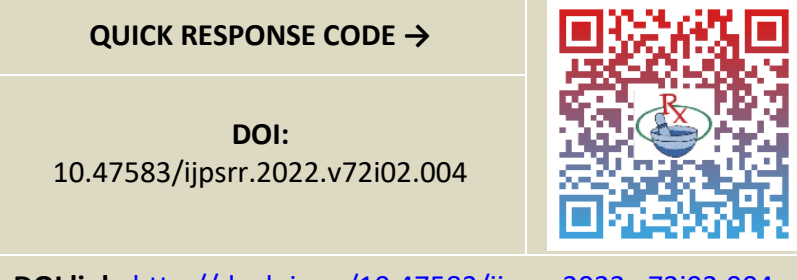

DOI link: http://dx.doi.org/10.47583/ijpsrr.2022.v72i02.004

\section{INTRODUCTION}

W ith a turnover of around $\$ 500$ billion, drug abuse is the third largest business in the world, next to petroleum and arms trade. About 190 million people all over the world consume one drug or the other. ${ }^{1}$ Drug abuse has become a universal and growing issue of concern to humanity. The illicit drugs have multiple consequences to health, society and economy. These consequences include health: mortality, morbidity, psychiatric and physical disorders; social: accidents, absenteeism, family disintegration, prostitution, organized crime etc; and economic: finances spent on developing services, drain on national resources, loss of productivity, etc. $^{2}$

The consumption of psychotropic drugs, whether on medical prescription or as self-medication, has been an integral part of the twentieth century especially among young population. ${ }^{3-4}$ In this modern era the ideas of taking psychotropic substance among youngster is to make them feel better about living in a modern world, depression, Ioneliness, tension, Relaxation, Self-medication, Financial burdens, Career pressures, School pressures, Peer and Social Pressure Abuse and trauma, Boredom, to fit in Curiosity and experimentation, Rebellion and to be in control. ${ }^{5-6}$

The prevalence of psychotropic drug use in the general population varies greatly between different states in INDIA. An estimated average 183,000 drug-related deaths were reported in 2012. Globally, it is estimated that in 2012, between 162 million and324 million people, corresponding to between $3.5 \%$ and $7.0 \%$ of the world population aged 15-64, had used an illicit drug mainly a substance belonging to the cannabis, opioid, cocaine or amphetamine-type stimulants group at least once in the previous year. ${ }^{7}$ According to year 2020 around fifty-nine thousand eight hundred and six (59806) cases were found in INDIA in which Uttar Pradesh topping among states with 11 thousand cases followed by Punjab with Six thousand nine hundred and nine (6909) cases. $^{8}$

Drug abuse directly influences the economic and social aspects of a country and resulting in increase in crime and suicide activities. ${ }^{9}$ According to the report of Ministry of Social Justice and Empowerment, Government of India and AlIMS only $1 / 4$ th (25 percent) of drug abusers receive treatment and rest of them do not receive any treatment resulting in more and more addiction towards psychotropic substance. ${ }^{10}$

Aim of this study-Through this Case Study we have targeted the growing cases of Drug Abuse cases and studied the trend of last few years and came up with the 
challenges faced, solution on the challenges and the conclusion of complete case study.

\section{Benchmark execution for lucid}

The goals of drug abuse treatment are aimed at stopping drug-seeking and use, preventing complications of drug withdrawal, rehabilitation, maintaining abstinence, and preventing relapse. Treatment of drug abuse is often an extended process involving multiple components including:

$\checkmark$ Cognitive behavioural therapy to work on thought patterns and behaviour

$\checkmark$ Meditation, yoga, exercise

$\checkmark$ Family therapy to help the family understand the problem and to avoid enabling drug use

$\checkmark \quad$ Identification and treatment of coexisting conditions

$\checkmark$ Medications to decrease cravings, block withdrawal symptoms, counteract drug effects, or to cause unpleasant side effects if a drug is used

$\checkmark$ Motivational incentives to reinforce abstinence

$\checkmark$ Motivational interviewing to utilize a person's readiness to change behaviours

$\checkmark$ Rehabilitation to assist those with severe addiction or coexisting mental illness through the initial stages of quitting

$\checkmark$ Support groups.

$\checkmark$ Modify their attitudes and behaviours related to drug use

$\checkmark$ Increase healthy life skills

$\checkmark$ Persist with other forms of treatment, such as medication. ${ }^{11-13}$

\section{STATISTIC AND SCRUTINY}

\section{State wise trend}

\section{Year: 2017}

In the year 2017, the total number of reported cases were approx. sixty-three thousand one hundred and twenty-six (63126). Here also the number of cases coming from the states are way more surplus than that from the union territory. From the states the number of reported cases were sixty-two thousand one hundred and twenty-six (62126) and from the union territory the number of reported cases is around six hundred and seventy-four (674).

In Graph 1, it is distinctly visible that the number of cases coming from Maharashtra are at the extreme nearly covering $23 \%$ of the total cases from the states. Then at the second position Punjab covering $19 \%$ of the cases from the total. Later, Kerela wrapping $15 \%$ of the total. Afterwards Uttar Pradesh at the fourth position wrapping up $12 \%$ of the entire cases. At the fifth position, Tamil Nadu is standing covering $6 \%$ of the complete cases from the states. And rest of the portion or the drug cases were reported from other states. ${ }^{14}$

Table 1: State wise trend 2017

\begin{tabular}{|l|l|l|}
\hline Sr. no & States & No. of cases \\
\hline $\mathbf{1}$ & Maharashtra & 14634 \\
\hline $\mathbf{2}$ & Punjab & 12356 \\
\hline $\mathbf{3}$ & Kerala & 9244 \\
\hline $\mathbf{4}$ & Uttar Pradesh & 7439 \\
\hline $\mathbf{5}$ & Tamil Nadu & 3812 \\
\hline $\mathbf{6}$ & Others & 15641 \\
\hline
\end{tabular}

Graph 1: State wise trend 2017

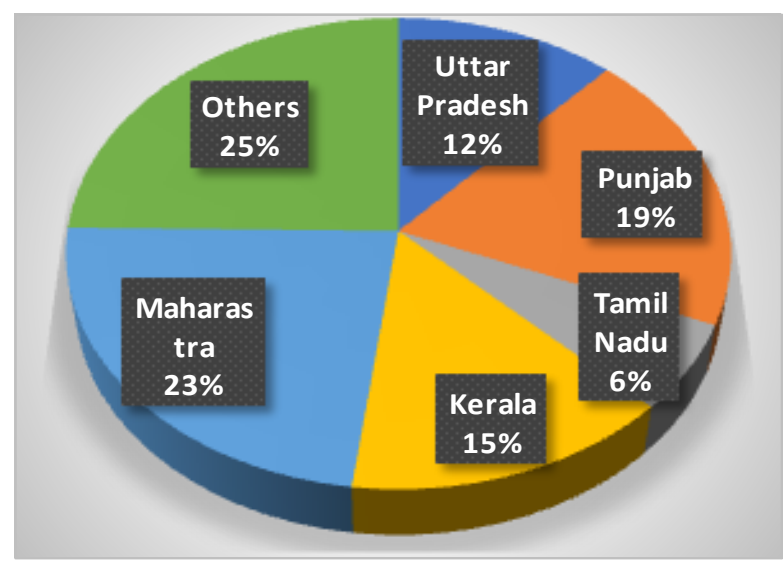

\section{Year: 2018}

In the year 2018, like an always trend here also the reported cases coming from states have accelerated from the union territories cases. This time the cases coming from the states are sixty-two thousand three hundred and seventy-one (62371). And the cases emerging from the union territories were seven hundred and sixty-six (766).

All over India there are five states which always highlighted with respect to high consumption of drugs. Maharashtra and Punjab standing on the first position with the highest percentage of $19 \%$. Later Uttar Pradesh and Kerala respectively with $14 \%$ of drug consumption from the entire number of cases. Lastly, Tamil Nadu with $6 \%$ coverage of the complete count of the cases. And the left over $28 \%$ comes from the other regions and states of the country.

Table 2: State wise trend 2018

\begin{tabular}{|l|l|l|}
\hline Sr. no & States & No. of cases \\
\hline $\mathbf{1}$ & Maharashtra & 12195 \\
\hline $\mathbf{2}$ & Punjab & 11654 \\
\hline $\mathbf{3}$ & Uttar Pradesh & 8821 \\
\hline $\mathbf{4}$ & Kerala & 8724 \\
\hline $\mathbf{5}$ & Tamil Nadu & 3717 \\
\hline $\mathbf{6}$ & Others & 17206 \\
\hline
\end{tabular}




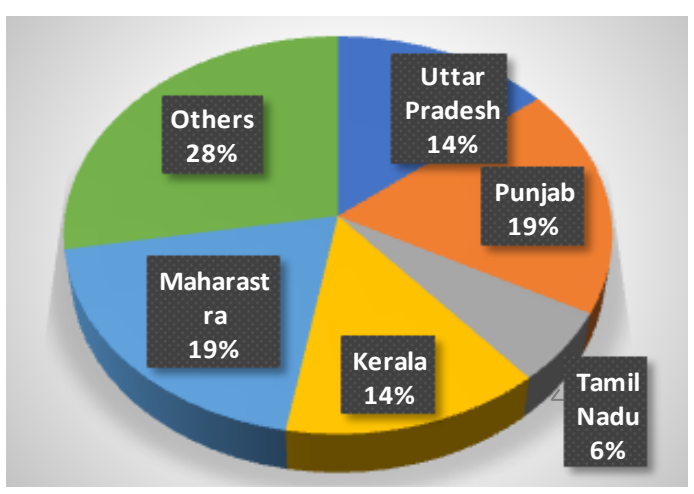

Graph 2: State wise trend 2018

\section{Year: 2019}

In the year 2019 the number of cases increased wildly with the number of cases reaching upto seventy-one thousand six hundred and seventy-eight (71678). Out of this the number of cases coming from the states were fifty-nine thousand eight hundred and six (59806) and from the union territories the number reaching upto one thousand and one (1101).

In this year also the topmost states are Maharashtra, Punjab, Uttar Pradesh, Kerala and Tamil Nadu. As always, the highest one is Maharashtra with the percentage of $20 \%$. Then Punjab ranking on the second position with $16 \%$ of the complete consumption from the states. Later on,Uttar Pradesh and Kerala with 14 and 13 percentage respectively of the entire consumptions. Lately, the remaining $31 \%$ of the consumptions comes from the other regions of the country. ${ }^{14}$

Table 3: State wise trend 2019

\begin{tabular}{|l|l|l|}
\hline Sr. no & States & No. of cases \\
\hline $\mathbf{1}$ & Maharashtra & 14158 \\
\hline $\mathbf{2}$ & Punjab & 11536 \\
\hline $\mathbf{3}$ & Uttar Pradesh & 10198 \\
\hline $\mathbf{4}$ & Kerala & 9245 \\
\hline $\mathbf{5}$ & Tamil Nadu & 4329 \\
\hline $\mathbf{6}$ & Others & 22212 \\
\hline
\end{tabular}

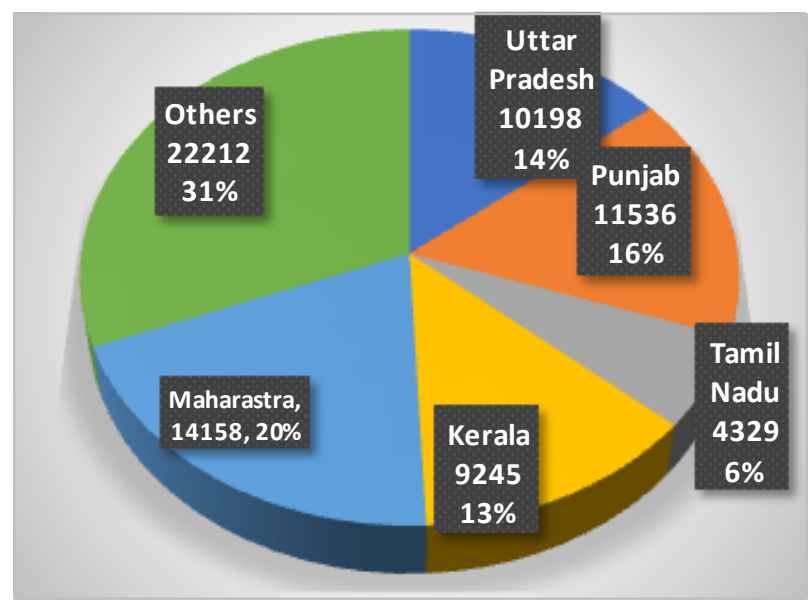

Graph 3: State wise trend 2019

\section{YEAR: 2020}

In 2020, the total number of cases all over India was around fifty-nine thousand eight hundred and six (59806). Out of this the number of cases coming from the states are fifty-seven thousand and six hundred (57600). The Union territories were way less than the cases from the states. They were almost less than 2 percent of the states. In union territory the cases reported were around two thousand two hundred and six (2206). The number of cases coming from the states are usually extremely higher than the UTs.

But at the same time, we have 6 topmost states consuming drugs. Those are Uttar Pradesh, Punjab, Tamil Nadu, Kerala, Maharashtra, Karnataka. This time the highest drug consumers are from Uttar Pradesh with $19 \%$ of the entire count. Then Punjab with almost $12 \%$ of the consumptions. Later Tamil Nadu and Kerala with the usage of $9 \%$ both respectively. In 2020, A great decline in the drug consumptions coming from Maharashtra with only $8 \%$ of the consumptions. Along with this, a new entry of Karnataka whose usage is of $6 \%$ from the total cases. The remaining $38 \%$ are reported from the other regions and states of the country. ${ }^{15}$

Table 4: State wise trend 2020

\begin{tabular}{|l|l|l|}
\hline Sr. no. & States & No. of cases \\
\hline $\mathbf{1}$ & Uttar Pradesh & 11000 \\
\hline $\mathbf{2}$ & Punjab & 6909 \\
\hline $\mathbf{3}$ & Tamil Nadu & 5403 \\
\hline $\mathbf{4}$ & Kerala & 4968 \\
\hline $\mathbf{5}$ & Maharashtra & 4717 \\
\hline $\mathbf{6}$ & Karnataka & 2766 \\
\hline
\end{tabular}

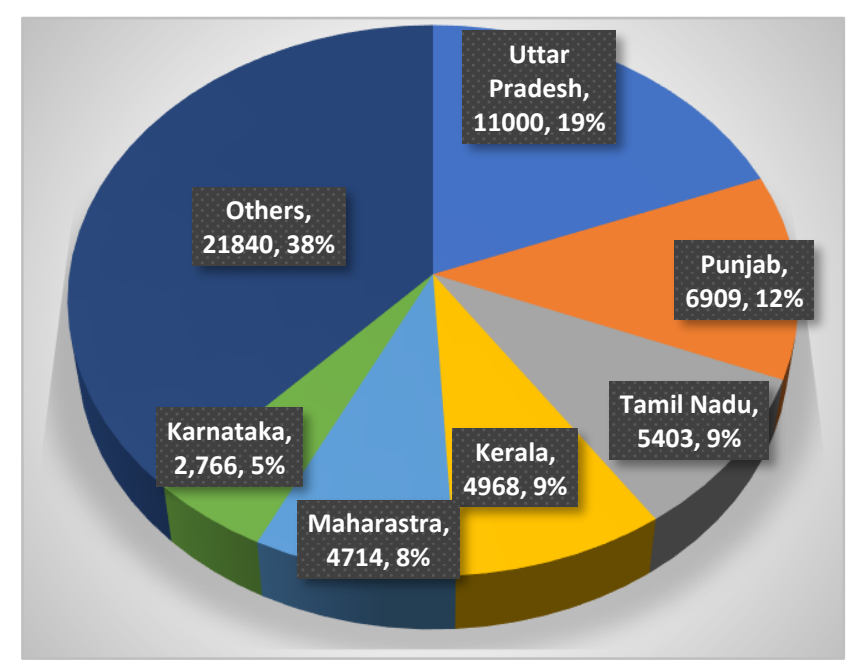

Graph 4: state wise trend 2020

\section{Narcotic Drugs Abuser with Respective to Age}

Nationally, the mean age of drug using subjects was 35.3 years. The largest numbers of drug abusers were found in the age group 31-40 cohort (36.9\%), followed by the 21-30 years age group (33.1\%). About 5 percent of users in the 
sample were aged $\mathbf{2 0}$ years or below. One fourth of drug abusers were more than 40 years old. ${ }^{16-17}$

Table 5: User percentage

\begin{tabular}{|l|c|}
\hline Age & User percentage \\
\hline $\mathbf{2 0}$ & $5 \%$ \\
\hline $\mathbf{2 1 - 3 0}$ & $33.1 \%$ \\
\hline $\mathbf{3 1 - 4 0}$ & $36.9 \%$ \\
\hline $\mathbf{2 4 0}$ & $\mathbf{2 5 \%}$ \\
\hline
\end{tabular}

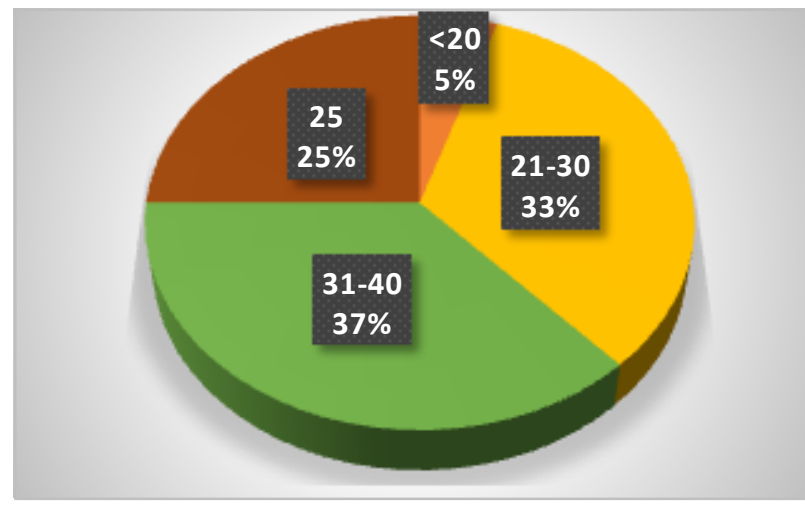

Graph 5: User percentage

Table 6: States contributed young abuser those below 20 and above 40 years

\begin{tabular}{|c|c|c|c|}
\hline States & Percentage (\%) & $\begin{array}{c}\text { States } \\
\text { (Below 20 years) }\end{array}$ & $\begin{array}{c}\text { Percentage } \\
\text { (\%) }\end{array}$ \\
\hline Mizoram & 37.9 & Tamil Nadu & 45.8 \\
\hline Jammu and Kashmir & 18.5 & Kerala & 44.8 \\
\hline Nagaland & 16.7 & Goa & 41.7 \\
\hline & & Karnataka and Andhra Pradesh & $39($ each) \\
\hline
\end{tabular}

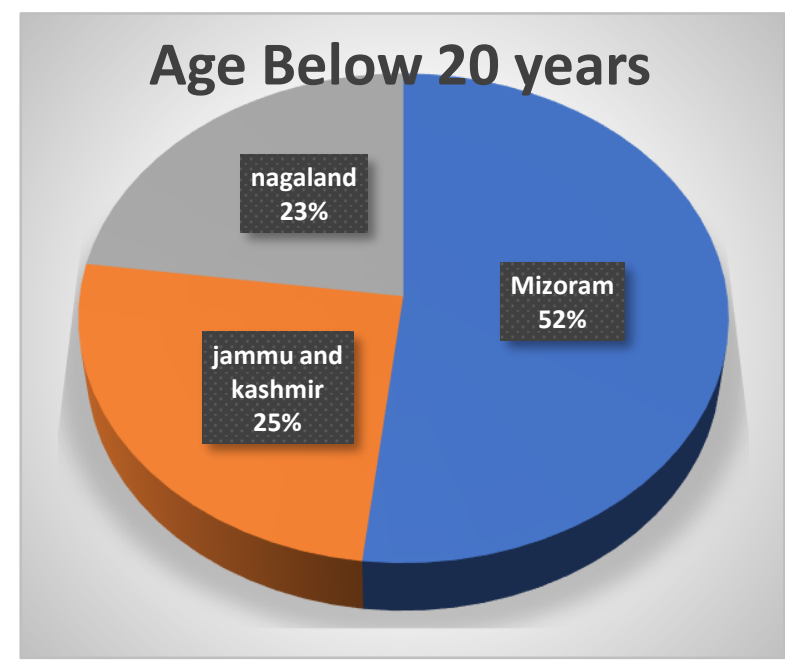

a

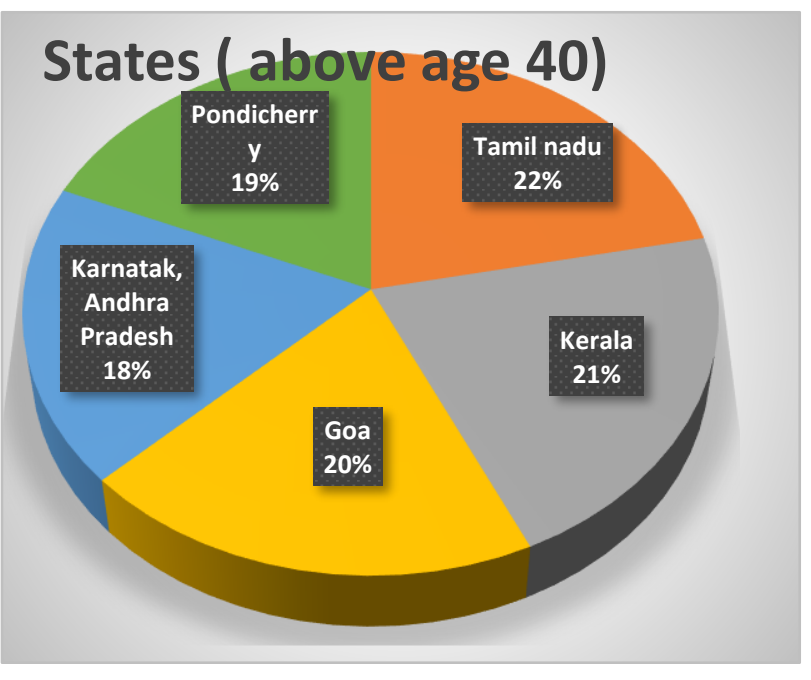

b

Graph 6: States wise trend with respect to age initiation

A few states contributed large numbers of young drug abusers i.e.: those 'below 20 years' of age. These young abusers were mostly from Mizoram (37.9\%), Jammu and Kashmir (18.5\%) and Nagaland (16.7\%). Older subjects i.e.: those 'above 40 years,' were more frequently reported from Tamil Nadu (45.8\%), Kerala (44.8\%), Goa (41.7\%), Pondicherry, Karnataka and Andhra Pradesh (39\% each).

The mean age of initiation into drug abuse was 24.0 years. Nearly one-tenth of users (9.7\%) started before reaching 15 years of age, while a little more than one-fourth started when they were between 16 and 20 years old. Almost half of the sample started using drugs between the ages of 21 and 30 years. Early onset of drug use (use before 15 years of age) was more frequently reported from Mizoram, Meghalaya, Rajasthan, Jammu and Kashmir, and Nagaland.

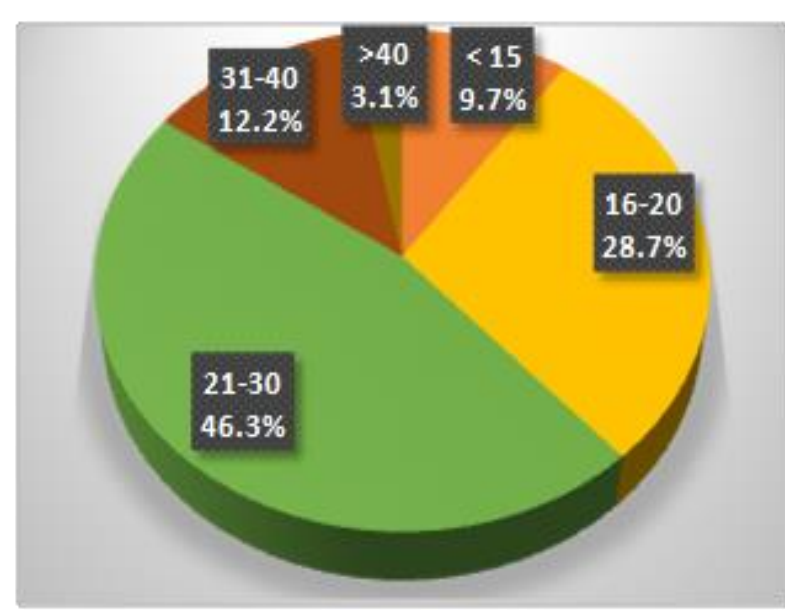

Graph 7: Age of initiation of drug use 
Table 7: Mean age of initiation into drug abuse

\begin{tabular}{|c|c|}
\hline Age & Percentage \\
\hline <15 years & 9.7 \\
\hline 16- 20 years & 28.7 \\
\hline 21- 30 years & 46.3 \\
\hline 31- 40 years & 12.2 \\
\hline >40 years & 3.1 \\
\hline
\end{tabular}

\section{Gender}

An overwhelming majority of the subjects were men (97.2\%). There were a few female drug abusers and they were more often reported from Andhra Pradesh (10.5\%), Manipur (9.8\%) and Mizoram (6.9\%). ${ }^{15-16}$

In India, about 0.2 per cent of men and 0.01 per cent of women aged $10-75$, an estimated 1 million people in total, reported in year 2018 for cocaine use. ${ }^{18}$

Table 8: Gender wise usage of drug

\begin{tabular}{|c|c|c|}
\hline Gender & States & Percentage (\%) \\
\hline Male & All over India & 97.2 \\
\hline Female & Andhra Pradesh & 10.5 \\
\hline & Manipur & 9.8 \\
\hline & Mizoram & 6.9 \\
\hline
\end{tabular}

\section{Literacy Wise}

A significant number of treatment seekers in the study were educated with only about 15 percent of the sample being illiterate. About 42 percent had completed higher secondary schooling or above. About 12 percent were graduates. Higher proportions of illiterate subjects were reported from Rajasthan (34.4\%), Andhra Pradesh (28.0\%) and Uttar Pradesh (25.7\%). By contrast, higher levels of education were found in Mizoram, Nagaland, Himachal Pradesh and Assam. ${ }^{14-15}$

Table 9: Literacy Wise

\begin{tabular}{|c|c|}
\hline Literacy level & Percentage (\%) \\
\hline Illiterates & 15 \\
\hline Higher secondary & 42 \\
\hline Graduates & 12 \\
\hline Others & 31 \\
\hline
\end{tabular}

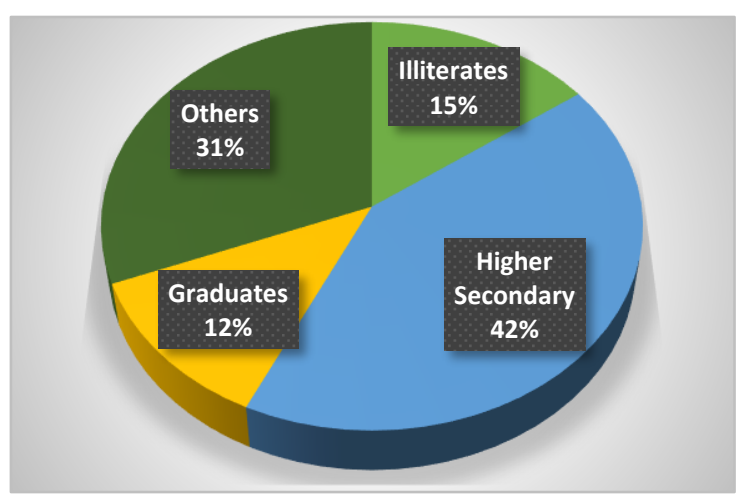

\section{Customary Used Drugs}

Cannabis, heroin and opium emerged as the most common drugs abused among treatment seekers. The majority of respondents were abusing, Cannabis (11.6\%), followed by heroin (11.1\%) and opium (8.6\%). Very few reported abuses of other drugs like propoxyphene, barbiturates, hallucinogens and inhalants (around $<2 \%$ each). Amphetamines were the least abused drugs (0.2\%). Nearly 19 percent of drug abusers have reported abuse of several other compounds like tobacco products, ayurvedic medicines and non-narcotic painkillers. ${ }^{19-20}$

Table 10: Drug wise consumption

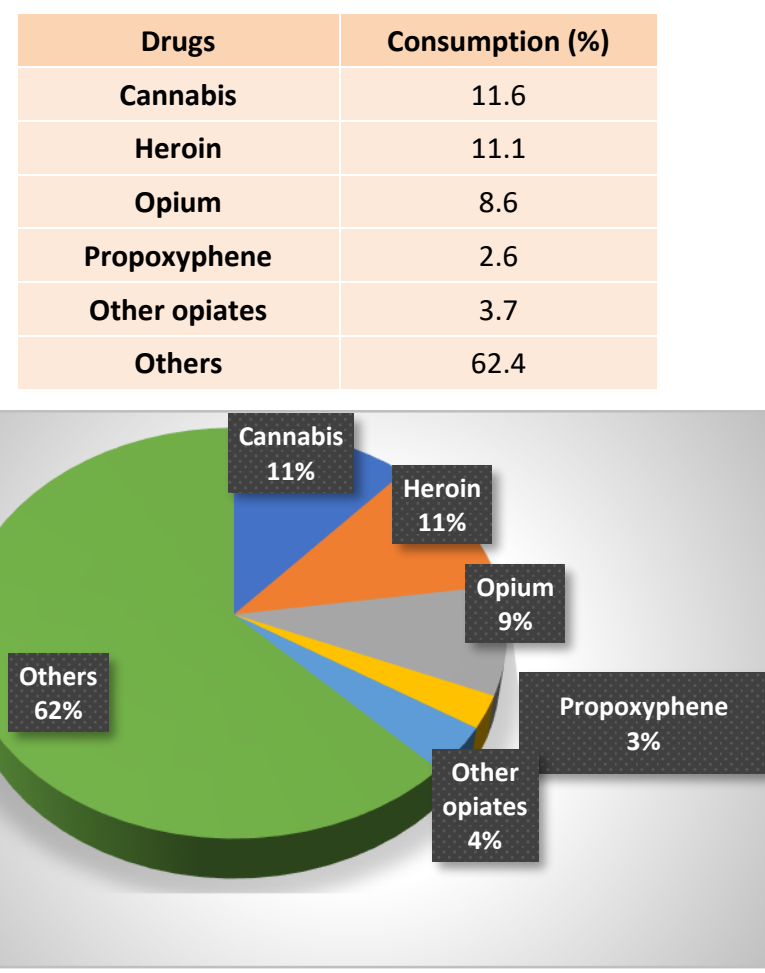

Graph 9: Drug wise consumption

1. Cannabis: When considering a larger timespan, the period 2009-2019, the countries seizing the largest total amounts of cannabis herb worldwide were, in order of the amounts seized, the United States, Mexico, Paraguay, Colombia, Nigeria, Morocco, Brazil, India and Egypt. ${ }^{21}$ Cannabis was reported from all the states except Jammu \& Kashmir. The states contributing the largest numbers of cannabis users to the sample were Uttar Pradesh (20.8\%), followed by Bihar (18.6\%), Kerala (15.8\%), West Bengal (7.4\%) and Maharashtra (7.0\%)

2. Heroin: Amongst the 2246 heroin in the study, none were from Himachal Pradesh or Tripura. The largest numbers of heroin abusers were found in Uttar Pradesh (17.3\%), followed by Delhi $(16.3 \%)$, West- Bengal (15.0\%), Manipur (10.1\%) and Bihar (10\%)

3. Opium: Altogether 1725 opium, were reported in the sample. There were no cases of opium abuse reported from Mizoram, Tamil Nadu and Tripura. The state with

Graph 8: Literacy Wise 
the largest number of opium abusers was Punjab (56.3\%), followed by Rajasthan (11\%)

\section{Statewise Utilization of Distinct Drugs}

According to Narcotics Control Bureau, Rajasthan and Maharashtra are the topmost user of Cannabis and Opium respectively whereas Manipur and Delhi are having maximum users of Heroin drug. The reason for high use of narcotics in Rajasthan, Punjab and Manipur is common international borders which is one of the most common ways of drug smuggling. ${ }^{16-17}$

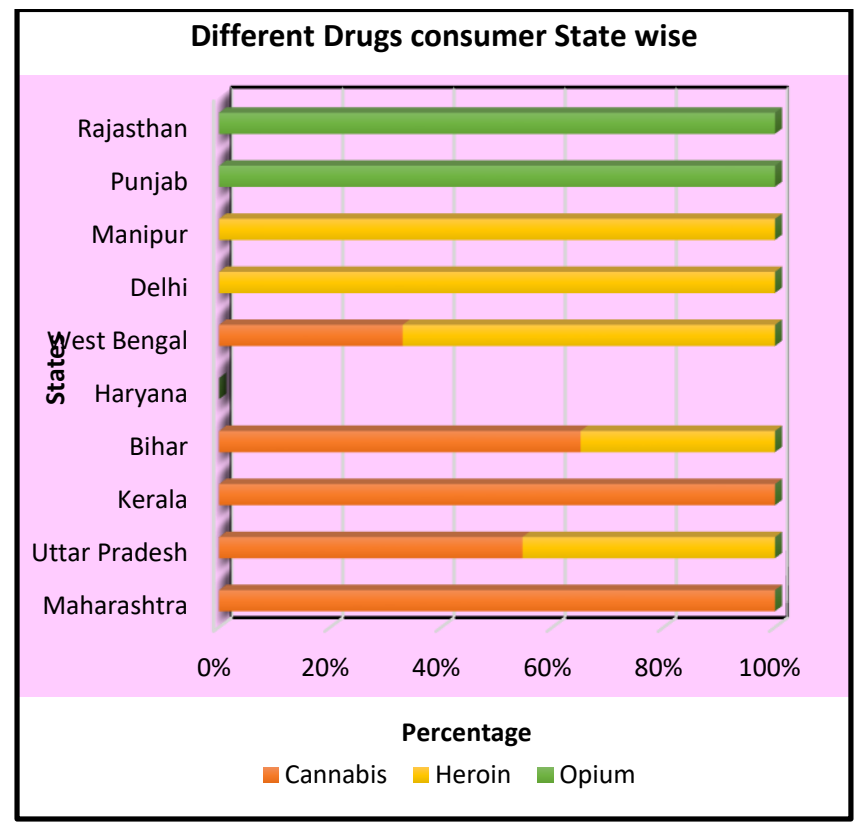

Graph 10: Different Drugs Consumer State wise

\section{Suicidal Cases Due to Drug Abuse}

Every now and then we get to hear about the suicidal cases in the newspaper taking place due to drug abuse. These suicides are due to various reasons like lack of drugs available to the victims, mental depressions, health issues, financial issues and many more. And on an average every year the number increases up to $10 \%$. The following data shows the yearly suicidal taking place from the year 2010 to 2019..$^{21-22}$

Table 11: Suicides due to drug abuse

\begin{tabular}{|c|c|}
\hline Year & No. Of cases \\
\hline 2010 & 3343 \\
\hline 2011 & 3658 \\
\hline 2012 & 4008 \\
\hline 2013 & 4591 \\
\hline 2014 & 3647 \\
\hline 2015 & 3670 \\
\hline 2016 & 5199 \\
\hline 2017 & 6705 \\
\hline 2018 & 7193 \\
\hline 2019 & 7860 \\
\hline
\end{tabular}

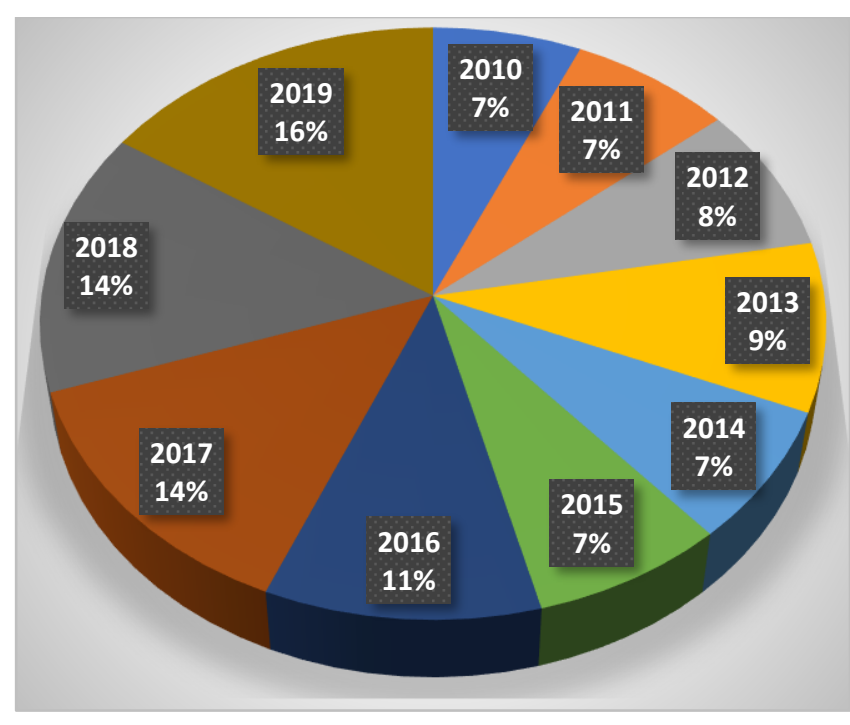

Graph 11: Suicides due to drug abuse

\section{Production of LICIT (Legal) Opium Drugs Since 1997 (Metric tons at $\mathbf{7 0}$ degrees consistency)}

According to provisional data from the Central Bureau of Narcotics, the total quantity of opium harvested in 2005 (March - April) declined by more than half to 439 metric tons. This was the result of a conscious decision by the union government to reduce the number of hectares under cultivation. The number of hectares harvested in 2005 was 7,833 , down from 21,141 in 2004 . The number of cultivators who actually tendered opium was 79,016 , down from the 2004 total of 98,555 . The average yield declined minimally from 57.07 to $56.04 \mathrm{kgs}$ per hectare at 70 degrees consistency. ${ }^{23}$

Some of Reason for decline of production of opium are,

1) Strict Licensing Condition

2) Strict Terms and Condition

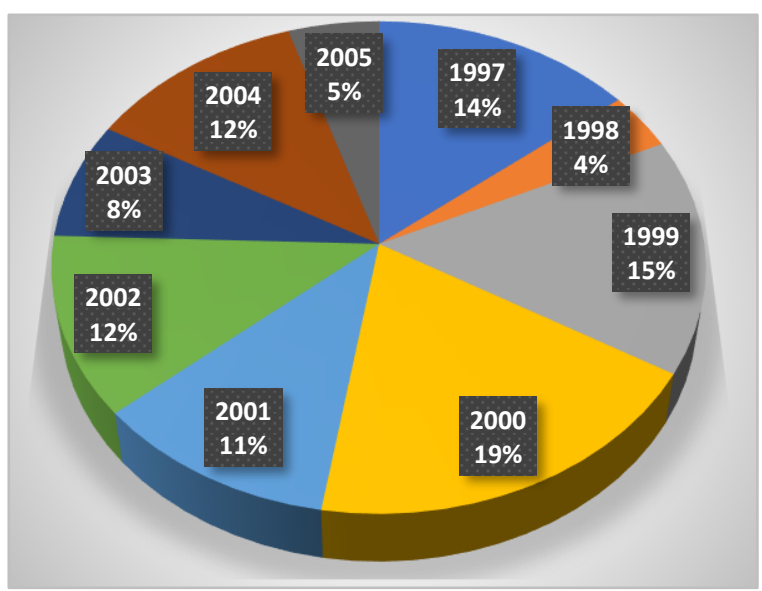

Graph 12: Licit Opium Production in Metric Tons

Statistical Analysis: Descriptive statistics were applied to the collected data using Microsoft Excel 2019 software.

\section{Recommendation}

Several fieldwork studies found that many people, especially the youths are eager to get rid of drugs. But 
unfortunately, they hardly get a way. It's an alarming situation and a sign of danger for upcoming generation. So, we have come with some recommendation in order to control of drug addiction. They are as follows:

$\checkmark$ Leaders of social institutions like schools, colleges, clubs etc. should come forward to build resistance against drugs.

$\checkmark \quad$ The NGO'S can play vital role in the awareness and rehabilitation processes.

$\checkmark \quad$ Can take help of Support Groups and spread more and more awareness among society Mass Education.

$\checkmark \quad$ The Narcotics Control Bureau are doing their job flawlessly, but there should be restructuring in Laws, more strict and immediate action should take place among drug peddlers.

$\checkmark \quad$ Last but not the least, Meditation, Yoga's, Pranayams should be promoted.

\section{CONCLUSION}

A Survey is a complex material as it contains too many data and multiple sources. Moreover, it has got the involvement of facts over theory. So does this survey have it. Here we have tried to bring and picturize the absolute scenario of drug consumption and its outcomes. This Survey has more concern with India and its states. From the above material we get to see that Punjab and Maharashtra are the two states which are highly have their stacks in the utilizations of narcotics. Wherein both were high on opium and cannabis respectively. On a yearly basis we see how the number of cases were low in the year of 2017 and have has an increase in the coming years. Lately the numbers declined in the year 2020 as the rules were made illiberal. Subsequently, it is been concluded that the male has been more affected and the age group which has the extreme usage is from 31-40 amongst which the population of literacy up to higher secondary are having more hands into it. To an astonishment we see how the young generation (age 21-30) is highly into these malpractices. As the exploitation has hiked up, according to a report a person taking psychotropic drugs are attempted to suicide in any stage of their life, the rate of suicidal cases due to drug abuse have also reached to the mark in the recent years.

Looking at the current scenario we have understood that the local drug peddler is a small aspect, whereas the biggest culprits are the big suppliers. They are the huge chunk who are making the maximum harm.

When it comes to the drug accused cases, there is hardly any difference between minor and the serious cases. Henceforth, it is the need of the hour for the participation of the public to spread awareness.

There is increase in drug abuse cases year by year It's very hard to know if this increase in the drug cases is actually due to some exigency or the generation has made it a fashion?

\section{REFERENCES}

1. Miller WR. Sanchez VC, Motivating young adults for treatment and life style change. In: Howard G., editor. Issues in alcohol use and misuse in young adults, University of Notre Dame Press, 1993: pp. 55-82.

2. Malhotra A, Mathur RS, Basu D \& Mattoo SK, Primer of addiction Drug deaddiction and treatment centre. Postgraduate Institute of Medical Education and Research, Chandigarh, 1997.

3. Pieters T and Snelders S: Mental ills and the hidden history of drug treatment practices. Psychiatry and mental health care in the twentieth century: Comparisons and approaches, eds. Amsterdam: Amsterdam University Press 2005.

4. Stephen S, Kaplan C and Pieters T, On cannabis, chloral hydrate, and career cycles of psychotropic drugs in medicine, Bulletin of the History of Medicine, 2006; 80: 95-114. DOI: 10.1353/bhm.2006.0041; PMID: 16549883

5. Bourke J: Fear; A cultural history. London: Virago, 2005.

6. United Nations Office on Drugs and Crime, World Drug Report 2014 (United Nations publication, Sales No. E.14.XI.7). http://www.unodc.org/wdr2014/en/druguse.html

7. Tomlinson J, The culture of speed; the coming of immediacy. London: Sage, 2007.

8. Ministry of Social Justice and Empowerment, Government of India, AlIMS, Chart: Dipu Rai, Sarfaraz Islam RN, Tabassum NE, Saifuzzaman AKM, Sarker MMI, A Case Study of Drug Abuse, Medicine Today, 2012; 24(02): 82-84.

9. Ministry of social justice and empowerment government of India, Magnitude of substance use in India, 2019; Annexure -I: 1-67.

10. Center for Behavioral Health Statistics and Quality (CBSHQ). 2014 National Survey on Drug Use and Health: Detailed Tables. Rockville, MD: Substance Abuse and Mental Health Services Administration; 2015.

11. Substance Abuse and Mental Health Services Administration (SAMHSA). National Survey of Substance Abuse Treatment Services (N-SSATS): 2013. Data on Substance Abuse Treatment Facilities. Rockville, MD: Substance Abuse and Mental Health Services Administration; 2014. HHS Publication No. (SMA) 14-489. BHSIS Series S-73.

12. Press Information Bureau, Government of India, (2013). Awareness and Education for the Prevention of Drug Abuse and Alcoholism. http://pib.nic.in/newsite/efeatures.aspx?relid=91579 
13. Government of India Ministry of Home affairs. https://www.mha.gov.in/MHA1/Par2017/pdfs/par20 21-pdfs/LS-20072021/459.pdf

14. National crime records Bureau Ministry of Home affairs, Crime in India 2020; Statics Volume-I

15. Drug Abuse Monitoring System - A Profile of Treatment Seekers. Treatment Centre Data. Data was available from 23 states, Page No. 6-15

16. Bethany KB, John Rodolico, and Kevin PH, MD, MHS, Sex, age, and progression of drug use in adolescents admitted for substance use disorder treatment in the northeastern United States: Comparison with a national survey, Substance Abuse, 2013; 34(3): 263272. https://doi.org/10.1080/08897077.2013.770424

17. Atul Ambekar and others, Magnitude of Substance Use in India 2019(New Delhi, Ministry of Social Justice and Empowerment, 2019). https://pib.gov.in/Pressreleaseshare.aspx?PRID=156 5001

18. Dechenla Tsering, Ranabir Pal, and Aparajita Dasgupta. Substance use among adolescent high school students in India: A survey of knowledge, attitude, and opinion. Journal of Pharmacy and
Bioallied Sciences, 2010; 2(2): 137-140, DOI: $10.4103 / 0975-7406.67005$

19. Kalpana L. and Kavya H.G., Knowledge Towards ATOD (Alcohol, Tobacco and other drugs: A case Study). Journal of Clinical and Diagnostic Research, 2012; 6(1): 38-41, DOI: JCDR/2012/3599:1867

20. UNODC (United nation office on Drugs and crime) World Drug report 2021. Drug Marketed trends: Cannabis and Opioids. 2021;3:16-20.

21. Tatjana D, Aleksandra D, Veselin D, and Vesna M. Drug Addiction as Risk for Suicide Attempts. , 2015; 27(3): 188-191, doi: 10.5455/msm.2015.27.188-191, PMID: 26236166

22. Miller NS, Mahler JC, Gold MS. Suicide risk associated with drug and alcohol dependence, Journal of Addictive Disease, 1991; 10(3): 49-61, DOI: 10.1300/J069v10n03_06, PMID: 1932152

23. UNODC (United nation office on Drugs and crime) Regional Profile South Asia, September-2005: Page no.31-33.

Source of Support: The author(s) received no financial support for the research, authorship, and/or publication of this article.

Conflict of Interest: The author(s) declared no potential conflicts of interest with respect to the research, authorship, and/or publication of this article.

For any question relates to this article, please reach us at: globalresearchonline@rediffmail.com New manuscripts for publication can be submitted at: submit@globalresearchonline.net and submit_ijpsrr@rediffmail.com

\begin{tabular}{|l|l|}
\hline Corresponding author biography: Mrs Megha S. Shah \\
\hline $\begin{array}{l}\text { Mrs. Megha S Shah is graduated and post graduated from Gujarat Technological } \\
\text { university (GTU) Gujarat, Post-graduation level taken specialization in } \\
\text { pharmacognosy, research topic was "Formulation and Evaluation of antlithiatic } \\
\text { activity of Varunadi kwath Churna". She has } 3.5 \text { years of teaching experience. She is } \\
\text { currently working as Assistant Professor at AISSMS College of Pharmacy, Pune, } \\
\text { India. }\end{array}$
\end{tabular}

